$$
=i
$$

NASA Technical Memorandum 103163

AIAA-90-2389

\title{
The International Space University
}

Kenneth J. Davidian

Lewis Research Center

Cleveland, Ohio

(NACA-TM-103163) THE INTFRNATIONAL SPACE

$N 90-22004$ UNIVERSITY (NASA) 11 P CSCL 22A

$$
\begin{array}{ll} 
& \text { Unclas } \\
03 / 20 & 0201594
\end{array}
$$

Prepared for the 26th Joint Propulsion Conference cosponsored by the AIAA, SAE, ASME, and ASEE Orlando, Florida, July 16-18, 1990 


\title{
THE INTERNATIONAL SPACE UNIVERSITY
}

\author{
Kenneth J. Davidian \\ National Aeronautics and Space Administration \\ Lewis Research Center
}

\begin{abstract}
The International Space University (ISU) was founded on the premise that any major space program in the future would require international cooperation as a necessary first step toward its successful completion. ISU is devoted to being a leading center for educating future authorities in the world space industry. ISU's background, goals, current form, and future plans are described. The results and benefits of the type of education and experience gained from ISU include technical reports describing the design projects undertaken by the students, an exposure to the many different disciplines which are a part of a large space project, an awareness of the existing activities from around the world in the space community, and an international professional network which spans all aspects of space activities and covers the globe.
\end{abstract}

\section{INTRODUCTION}

Any large-scale space project may require international cooperation because no one nation can provide the money, facilities, manpower, and other resources necessary to successfully complete it (ref. 1). Plans for the United State's Space Station Freedom, from Phase I to the mature configuration designs, all include international participation as an integral portion of the project. A program as ambitious as a lunar base or the Mars initiative may require extensive participation from other interested nations. Intemational cooperation has been cited since 1961 as a "principle motivation" of the space program (ref. 2), but it wasn't until recently that a long-term interchange between nations was begun in U.S. space activities. Therefore, the need to change from a uninational space program to international cooperative efforts will increase if large space projects are to be attempted in the future.
This change, however, will be made more difficult unless people are prepared to work alongside peers who don't speak the same language, weren't educated in the same way, don't approach problem-solving in a similar fashion, and don't express ideas in the same manner as themselves. An education of the process for transitioning from a uninational to a multinational system is necessary to insure that progress in space-related technological advances are not undermined by the lack of understanding of the multinational environment.

The International Space University (ISU) was conceived to begin this process. ISU provides training for people from different cultures on how to work together, and to promote space-related relations across frontiers, in order to begin eliminating barriers to productive work in future space programs. By bringing students together for a period of two months to study, attend classes, and work on a design project together, the students leam to overcome problems which stem from differences in national origin, native language, culture, and historical perception of one another. Perhaps the biggest benefit of ISU, one which cannot be measured quantitatively, is the payoff from building an international network of future space leaders in the period of nine weeks. Under ordinary conditions, this would take an entire career.

This paper outlines the beginnings of ISU, its purpose, goals, accomplishments, results, and benefits to the space community.

\section{BACKGROUND AND DESCRIPTION}

On 12 April 1987 at the SPACEFAIR conference held at the Massachusetts Institute of Technology (MIT), Todd B. Hawley, Peter H. Diamandis, and Robert D. Richards first presented the idea of the International Space University (ISU) to the Space Generation Foundation (SGF). The SGF was founded on 4 October 1985 "to develop 
projects to foster the peaceful exploration and development of space, and to prepare members of the Space Generation for unified efforts both on and off our planet Earth" (ref. 3). ISU was mandated to educate the future leaders of the space community in all disciplines relating to space activities.

ISU, as detailed in April 1987, has developed into a non-profit, non-governmental institution which is headquartered in the United States. To be a principle institution of education in the space industry, the following goals, paraphrased here from an ISU document, were established:

- to select, assemble, and instruct the best graduate students from all nations of the world,

- to provide a curriculum in the area of all space-related disciplines which will give the students the ability and knowledge to overcome future challenges and changes in the space industry,

- to develop leadership skills,

- to develop permanent personal relationships amongst the students and faculty,

- to develop and increase the international understanding and cooperation in existing and future space programs, and

- to develop the student's awareness of all the disciplines involved with a large space program.

International cooperation will play a major role in advanced and ambitious space projects, such as long-term human habitation off of the planet Earth. One of the founders of ISU, Peter H. Diamandis, sees ISU as accelerating humanity's move into space on a permanent basis (ref. 4). Other ideas as to what ISU's objectives are have been expressed in scientific and space-related periodicals. ISU "was designed to...create an intermational community of space professionals, a new breed of scientists and policy makers willing to set aside national differences to pursue commercial and scientific opportunities in space" (ref. 5). "ISU's objective is simply to fill the expanding need in industry, universities, and govermments for space professionals who are prepared to function in a broad spectrum of specialities crucial to the future of space exploration and operations" (ref. 6).

The three founders of ISU foresaw the initial ISU as being conducted as a summer session only, changing locations between prestigious academic institutions in different nations until 1992 when, in association with the International Space year, ISU would expand to a two year format at a permanent site with the ability to grant graduate-level degrees. In addition, ISU would then establish permanent "advanced campuses" in other locales around the world, to complement the overall educational program at ISU. The year-round format of ISU would benefit industry and universities by performing more in-depth research than is currently being accomplished. Access to orbiting space facilities for faculty, researcher, or student use is included in ISU's long-range plans.

Government leaders, scientists, space experts, and academicians, many of whom were present at the SPACEFAIR conference in April 1987, make up the Board of Directors and the Board of Advisors of ISU (Table 1). "Prototype" lectures were given during the founding conference to give the attendees a feeling for the type of course work which ISU would feature (ref. 7).

An initial funding requirement for operations and staffing was obtained via grants from corporations and foundations, and from the National Aeronautics and Space Administration (NASA). Supporters of ISU within NASA included former Associate Administrator for Space Station Freedom, Andrew J. Stofan, and former Head of the Office of Space Science, Burt Edelson (ref 5). Currently, contribution of funds for ISU are solicited by the foundation of ISU liaisons. Currently, these liaisons exist in ten different countries (including Canada, India, Japan, the People's Republic of China, Sri Lanka, Switzerland, the United Kingdom, the U.S., and the U.S.S.R.) and the European Space Agency. Today, ISU is sup- 
ported by over 100 corporate and govemment sponsors.

A faculty search for the first ISU summer session resulted in hiring 31 full-summer professors (primarily North American), 21 course advisors, and approximately 80 visiting faculty representing 15 nations. The chance to teach a select group of students, as well as the promise of a salary equivalent to a summer teaching position at Harvard University, provided the impetus for the faculty to accept the teaching posts.

The search for students began with the distribution of 5,000 applications world-wide, 350 of which were retumed meeting ISU's student selection requirements (Table 2). Final selection of 104 students from 21 nations was made by the ISU faculty. ISU's first summer session was held at MTT in Boston, Massachusetts between the dates of 20 June and 20 August 1988.

The curriculum for the summer sessions was developed in response to the realization that existing curricula at other universities were too narrowly focused and too compartmentalized. Specific curricula were developed for each discipline by teams of a course director, course advisors, and experts in the field. Goals of the nine-week sessions provide the attendees the opportunity to:

- learn about all areas of the exploration and development of space,

- take classes with and have access to the best instructors in the world in the different disciplines relating to space,

- interact with people from the world's leading academic institutions who have common interests,

- work together on a design project which is relevant and timely to the existing space programs in the world,

- talk about and assess goals, motivations, and ideals with respect to international cooperation in space, and

- share ideas for the future of space development.
Over 240 hours of course work and over 280 hours of project design work were completed by the students during the nine week summer session. The design project for the first summer session of ISU was a lunar base, referred to as the International Lunar Initiative. The first summer session was noted by the award of Aviation Week and Space Technology's "Laurels" mention of the founders of ISU and the successful completion of the MIT session (ref. 8).

The second summer session was held between the dates of 1 July and 31 August 1989 in Strasbourg, France at the Université Louis Pasteur (ULP). ULP was selected because it is recognized for its forte in science education and also for its affiliation with Nobel Prize winning scientists. Strasbourg, one of three meeting sites of the European Parliament, serves as a political center of western Europe and is accustomed to hosting large international events.

The number and national diversity of the students who met in Strasbourg increased with respect to the first summer session. The makeup of the faculty shifted away from a large US contingent toward a stronger European and Soviet representation from the first to the second summer session (Table 3).

A total of three design projects were completed by the students of ISU in Strasbourg; two "large" design projects, which were conducted over the entire nine-week period, and one "small" project, which only required three days for its completion. The "large" design projects were the Lunar Polar Orbiter (LPO), a satellite which would orbit around the moon's poles to make geologic and gravity maps of the entire lunar surface, and a Variable Gravity Research Facility (VGRF), designed to study the effects of low- and intermediate-gravity levels (from $0.16 \mathrm{~g}$ to $0.70 \mathrm{~g}$ ) on the human body in preparation for long-duration interplanetary travel. Each "large" project culminated with a day-long presentation by each group who worked on the project describing their portion of the work. The "small" design project, the Equatorial Spaceport, was the evaluation of the political, organizational, and technical requirements for a non-space-faring nation situated on 
the equator to construct and operate a launch facility. Final reports were generated for all three projects, and detailed appendices and an executive summary were composed for the LPO and VGRF projects.

Sites for the remaining three ISU summer sessions have already been selected, and include Toronto, Canada in 1990, Moscow, U.S.S.R. in 1991, and a location in Japan in 1992. After the completion of the 1992 summer session, ISU plans to open its doors on its permanent facility to begin year-round operations providing a Masters of Space Studies degree. The location of the permanent ISU campus has yet to be determined.

\section{EDUCATIONAL VALUE}

Emphasized in the ISU program is the value of an intemational perspective in solving problems and confronting issues specific to each discipline. Based on the author's experience within the discipline of engineering in general, and in the area of liquid rocket propulsion in particular, the approach of working with someone who comes from a very different background, culture, and educational system was enlightening. Many students had the rare opportunity to work closely with people from other countries which were, at that time, "off-limits" due to their governments" ideological differences.

Problems within the rocket propulsion industry are the same world-wide, however, the way these problems are solved are very different. One example is the design of turbomachinery historically used by the American and Soviet engineers for large launch vehicles. For a cluster of liquid rocket engines, the American engineers allotted one turbopump to each combustion chamber in the group of engines. The Soviets, on the other hand, took the approach of designing one pump for the entire cluster of engines. Neither approach is wrong and both have their technical advantages and disadvantages.

Solution methods to a problem were different based upon the emphasis of the educational background of the individual. Different educational systems emphasized the analytical and computational approaches to problem solving to varying degrees. Well matched groups of students working on a given project consisted of people with strong analytical skills (derivation of relevant equations) as well as people with strong computational skills (computer programming). The complement of these two approaches allowed the ISU students to thoroughly and realistically design a VGRF and LPO, perform the necessary trade-off studies, and tabulate, graph, collect, and describe all the data and results in a written report in a time period of approximately nine weeks. Differences of opinion on technical matters which were based on cultural perspectives were encountered within the working groups. Conflicting viewpoints for which no resolution was found, were developed and presented as viable problem solutions.

Exposure to differences in learning and working styles teaches the value of different perspectives, and how to work as a team, using the strengths of other people to accomplish their common goal.

Exposing each student to all of the other disciplines was a major strength of ISU. In addition to cultural differences, ISU helped reduce the barriers of discipline differences. All too often, members of one discipline are affected by restrictions on their work which are based solely upon another discipline's guidelines. For instance, engineers and scientists at ISU may not like the fact that others (i.e., politicians and lawyers) have ultimate power over their work, but at least they began to understand the how and why of the situation. Although total understanding may not have been achieved between all disciplines, the purposes, methods, and perspectives of each was taught.

A slightly different problem based on a lack of understanding between members of two disciplines was also addressed at an ISU directed studies lecture entitled "Inherent Conflicts Between Engineers and Life Scientists." Students gained experience in how to understand the perspective of individuals who have similar roles in different aspects of a large space program. Many opportunities were available after class for one student to talk with another as a departmental representative about issues which concerned both disciplines on the design project or about space related topics in general. 
Some of the additional benefits of ISU were those of communication skills in intercultural and interdisciplinary situations, education about national and international space efforts in all disciplines which are underway throughout the world, and a vast professional network made up of today's most prominent educators and experts in their field, as well as tomorrow's leaders in the world space community.

ISU students leamed to interact on a personal and professional level with individuals from other countries and cultures. The most common problem of intercultural communication was evidenced by the tendency of nativeEnglish-speakers to unwittingly dominate conversations. Non-native-English-speakers did not have enough time to formulate their thoughts into words before the topic would change and the conversation would move onto another topic. The native-English-speakers had to practice patience and restraint to allow others to express their opinions. Another typical difference between cultures was with the use of "brain-storming," a typically westem method of generating a large number of ideas quickly. Individuals from non-western cultures were not accustomed to voicing their opinions without thinking through their ideas first. Therefore, they were uneasy about aggressively putting forth ideas because they were uncomfortable with the procedure.

Aside from the communication experience gained by the students, the process of conducting international business, research, law, and relations was presented and explained in detail in the lectures. The need for international cooperation has been a way of life for members of the European community, but it is not yet a normal mode of operation for most of the other space-faring nations. To make progress toward large space programs, intemational cooperation may be a necessary step. ISU teaches how international cooperation works.

Probably the most important of all the benefits of the summer session, ISU provides the students with a firm foundation of personal bonds upon which are built strong and meaningful professional relationships. The network of intemational contacts which each student developed with other students and faculty is invaluable and would be otherwise unattainable in such a short time. This network will provide each individual a conduit for valuable information over the course of their careers.

Results from the summer sessions of ISU are the same as would be expected from any school or university. Participants were evaluated and reports were written. Students who participate in the nine-week summer session are evaluated by the faculty based on lecture attendance, class and project participation, and, in the case of the second summer session, the final exam score. The decision to include a written test in the 1989 summer session curriculum was made in order to provide feedback to the lecturers as to what material was comprehended and by whom, as well as to provide an indicator of student performance. Conversely, all lecturers were evaluated by the students and the issues of importance were discussed openly at "Town Meetings".

Reports from each of the projects were written by the students. Each report was composed of three parts: an executive summary, a final report, and a detailed appendix for technical support. Draft copies of the final reports for both the LPO and VGRF projects were finished by the end of the second summer session. Executive summaries for the VGRF project were distributed to the students on their last day of the summer session. A complete publication of all three portions of the reports is being prepared by the ISU staff.

\section{CONCLUDING REMARKS}

ISU was founded on the premise that for any large space program to succeed in the future, a substantial amount of intemational cooperation would be required. ISU provides education and training to people from different cultures to promote intemational cooperation and relations. Although the Apollo-Soyuz 
project required cooperation between the United States and the Soviet Union, real long-term international cooperation was begun for the U.S. with the Space Station Freedom program. Opportunities for international cooperation in the future will be plentiful as the large space-faring nations set out to accomplish goals which are more ambitious than the previous ones. The international agreements which would be required for this cooperation are highly complex. Workers who are not experienced in working with counterparts from different parts of the world will discover that making progress on the project may be more difficult than they anticipated. The experience gained at ISU could be put into practice through the use of liaisons. Liaisons could be employed at low levels of management and at the working level to foster cooperation and understanding between the partner organizations.

For the past two summers, over two hundred students have received training which will make these problems easier to surmount. They have leamed to work with their co-workers from different parts of the world, regardless of their cultural or national backgrounds. They have learned how to appreciate and work with members of different disciplines which are equally as important to the success of the overall project. They have developed an intemational support system and information network which will help them eliminate barriers which can hinder productivity.

\section{REFERENCES}

1. Air \& Cosmos Monthly, "Blueprint for the Red Planet", January/February 1990, page 69.

2. Logsdon, John M.: "The Decision to Go to the Moon: Project Apollo and the National Interest", The MIT Press, 1970, page 72.

3. Hawley, Todd B. and Diamandis, Peter H.:"ISU Executive Report", ISU 1988 Annual Report, page 4.

4. The Christian Science Monitor, "Lift-off for Space University", 19 July 1988.

5. The Scientist, "Space University Completes Its First Semester at MIT", 3 October 1988.
6. The Space Times, "The International Space University”, March-April 1989, pages 7-11.

7. Pravda, "International University", 14 April 1987.

8. Aviation Week and Space Technology, "Laurels 1988", 2 January 1989, page 12. 
Table 1. Board of Directors and Board of Advisors of the International Space University.

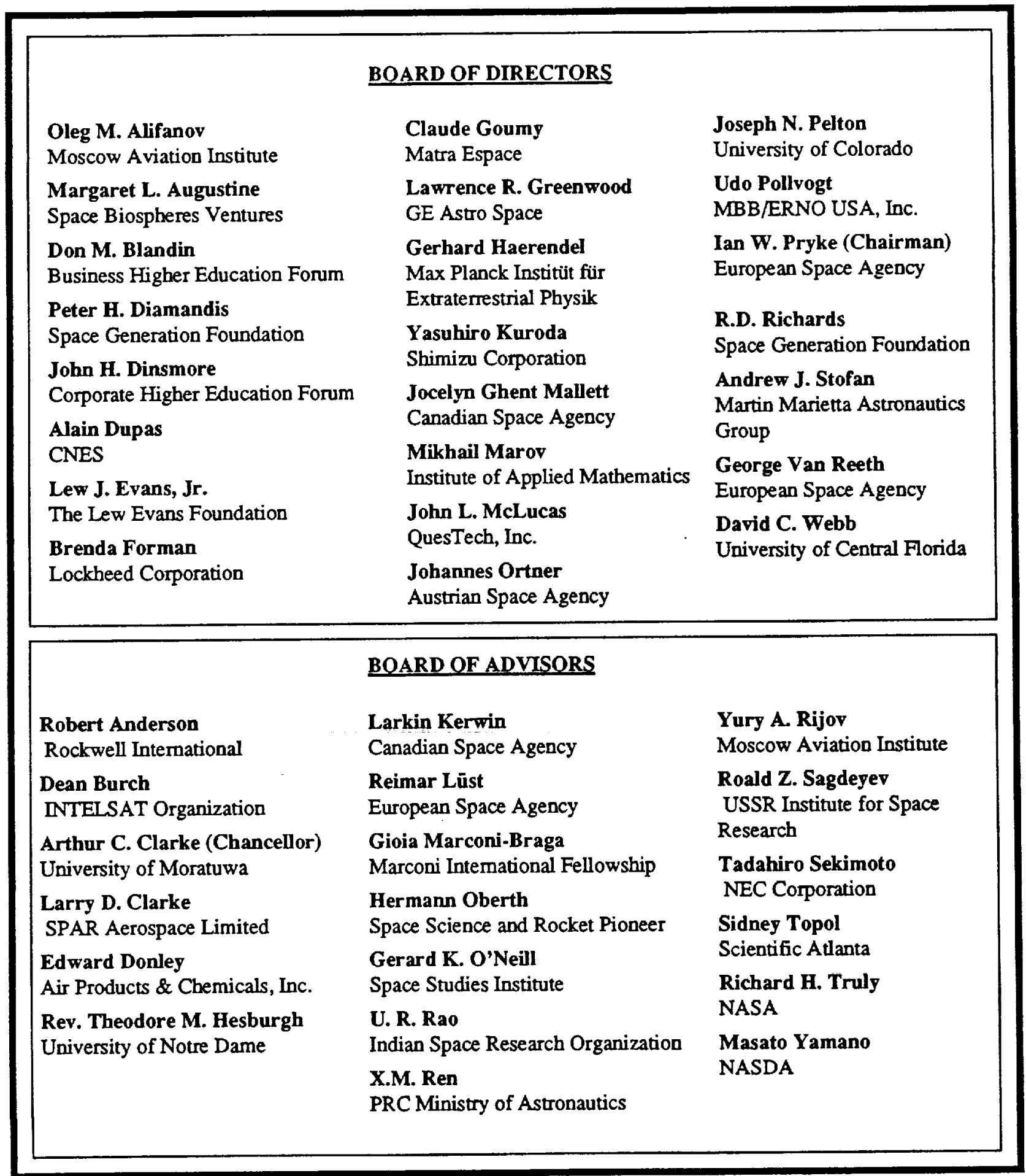


Table 2. List of ISU Student Selection Requirements.

\section{ISU Applicants are Required to Have:}

- Bachelor's degree (or equivalent) from an accredited university. Applicants are also expected to have a general understanding of the academic disciplines represented in the ISU curriculum.

\section{ISU Applicants Should Have:}

- Graduate student status: Applicants should be accepted in to or enrolled in a graduate level (e.g. Master's, Ph.D.) academic program. -or- Applicants should have completed graduate school no more than five years prior to the start of the ISU program.

-or-

- Professional experience in industry, govemment or academic research which follows after the successful completion of a bachelors degree (or equivalent). Professional experience of at least two years is preferred.

\section{Language Requirements:}

- English language fluency required of all applicants. Fluency to be documented by TOEFL exam (Test of English as a Foreign Language)

- Native English speakers should demonstrate fluency in a second language. Fluency level to be documented through a Declaration of Language Competence included in the ISU application for admission.

\section{Selection Criteria:}

- Excellence - ISU seeks students who have demonstrated outstanding ability in their chosen field of study, research or work.

- Leadership - ISU seeks leaders: individuals who have chosen to begin new initiatives and take on responsibilities, individuals who strive to lead humanity into space.

- Internationalism - ISU seeks students who are actively motivated to gain international understanding.

- Commitment - ISU seeks students who have consistently committed themselves to the development and exploration of space through their extended involvement in space related endeavors.

- Experience - ISU seeks students with work experience in the space industry or space related govermment agencies. 
Table 3. Students and Faculty Breakdown by Nationality for First and Second Summer Sessions.

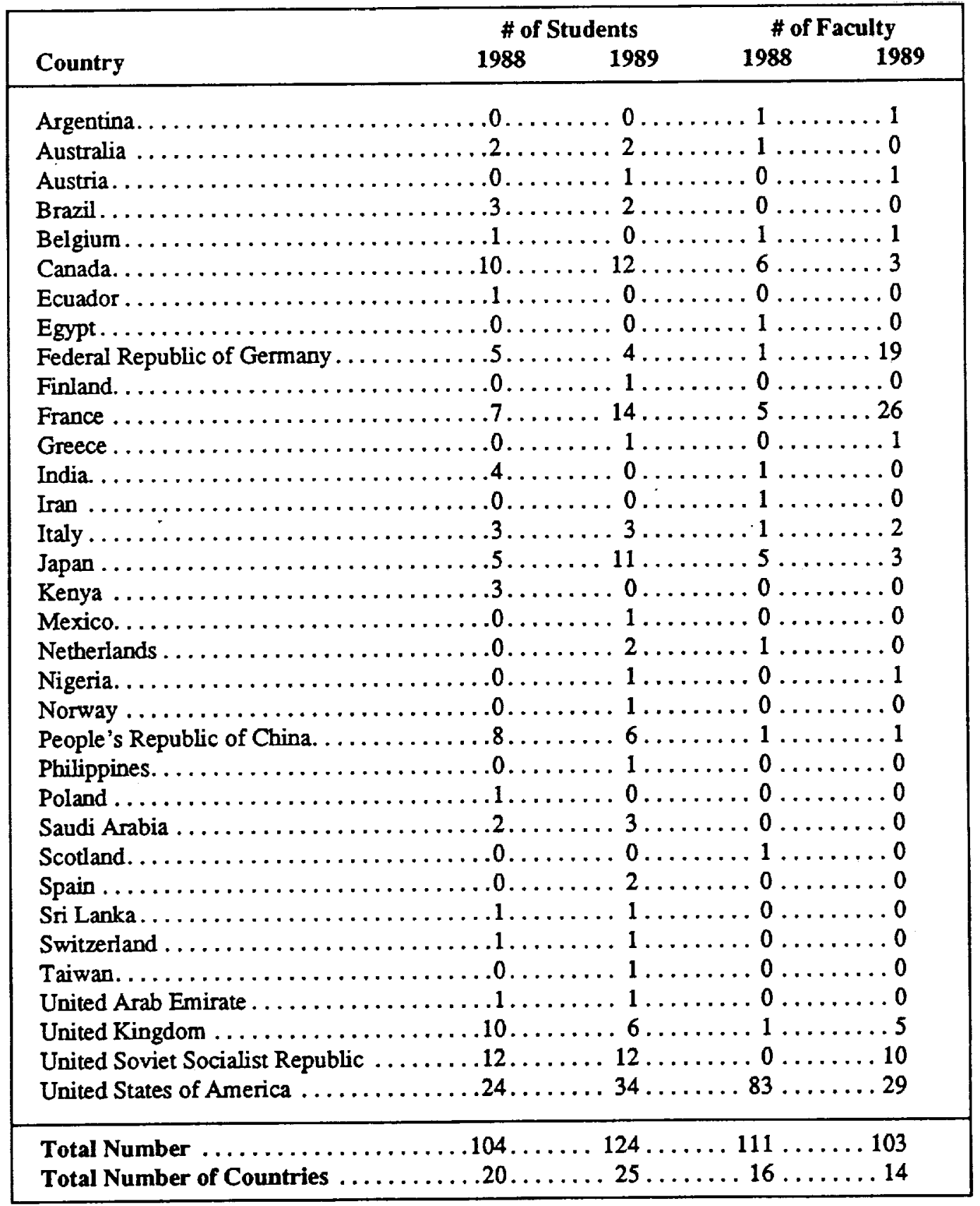




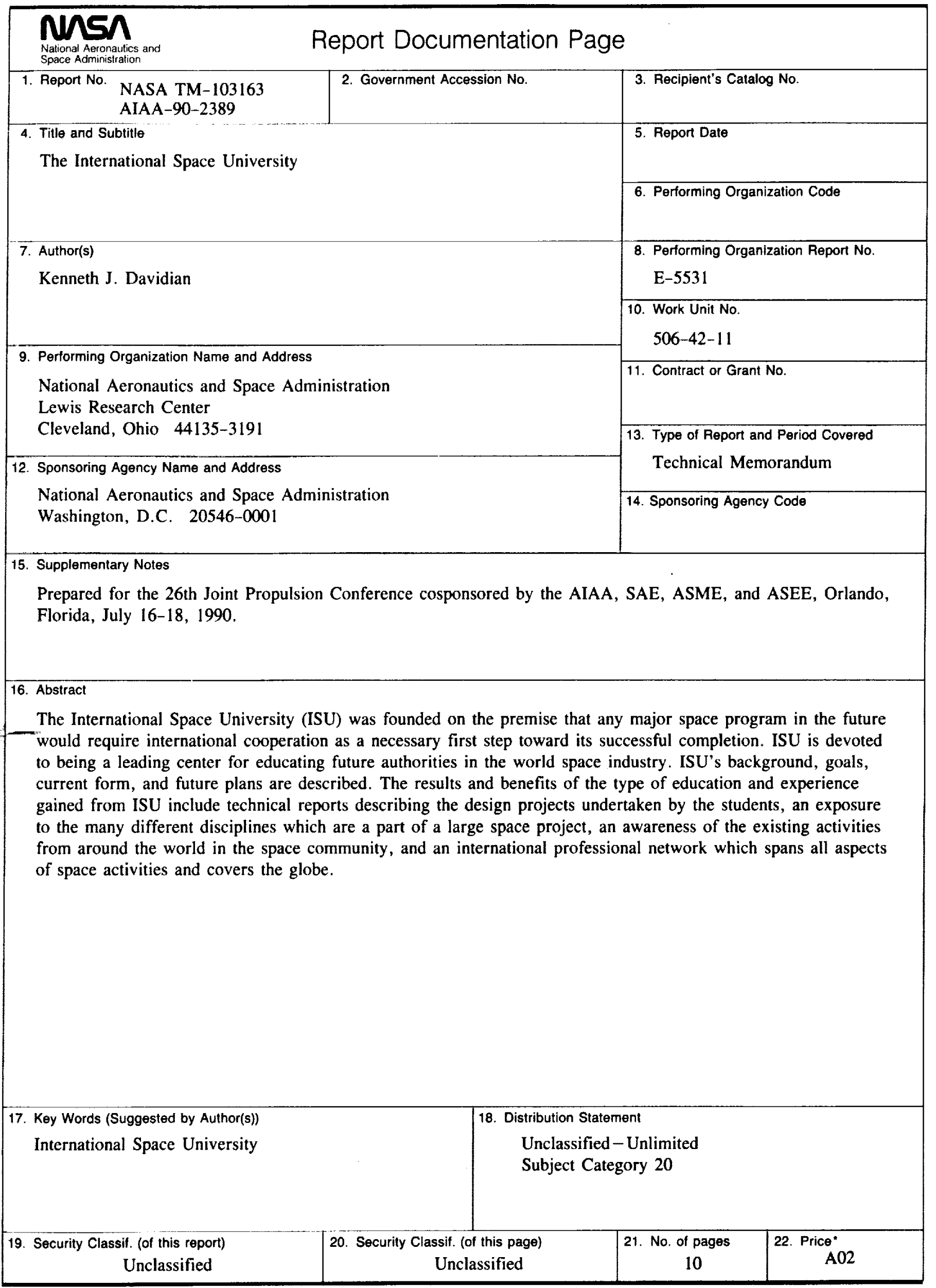

